\title{
Box-Scheme Based Delivery System of Locally Produced Organic Food: Evaluation of Logistics Performance
}

\author{
T. Bosona, G. Gebresenbet, I. Nordmark, D. Ljungberg
}

Department of Energy and Technology, Swedish University of Agricultural Sciences, Uppsala, Sweden. Email: Techane.Gari.Bosona@slu.se,tg.bosona@live.se

Received May $7^{\text {th }}, 2011$; revised June $18^{\text {th }}, 2011$; accepted June $30^{\text {th }}, 2011$.

\begin{abstract}
The local food systems such as fruit and vegetable box-schemes are gaining new profitable niche markets as the demand for local food is increasing. This paper presents the study made on box-scheme based local food supply system in Sweden, the Roslagslådan network, in which three distributors of locally produced organic food (LPOF) were the main actors. The objective of the study was to investigate the Roslagslådan LPOF supply network and evaluate its logistics performance. The study was based on literature review, interview, field measurement and route simulation and optimisation (in terms of route distance and driving time) analysis. The geographic information system (GIS) software was used to map the locations of the distributing companies and their delivery points (customer locations) while Route LogiX software was used for the simulation and optimisation analyses of routes for collection and distribution of LPOF, mainly vegetables and herb-based products. From the quantified information, the three companies distributed, on average about 134 boxes of LPOF to about 116 delivery points, once in two weeks period mainly during August-October. The distribution via Roslagslådan network was supplemented with other means of selling: on farm sale, open market sales and selling via supermarket. The route optimisation analysis resulted in significant savings in route distance and delivery time. The savings in distance were up to $76 \%, 23 \%$ and $32 \%$ for Company-1, Company-2 and Company-3 respectively while the corresponding savings in delivery time were up to $75 \%, 10 \%$ and $16 \%$. This reduction in distance and time led to positive improvement toward the environmental and economical issues enhancing the sustainability of local food systems.
\end{abstract}

Keywords: Sweden, Roslagslådan Network, Box-scheme, Locally Produced Organic Food, Route Analysis

\section{Introduction}

The local food systems are gaining new profitable niche markets as consumers start to value traceability and production quality of locally produced food over cheaper food grown and processed at unknown places around the globe. As a result, fruit and vegetable box-scheme based delivery systems are emerging as alternatives to conventional and centralized food delivery systems [1-3]. Although a common understanding of local food is its proximity to production place to customers, other characteristics such as small scale, greenness and socially sustainable have been associated with it. Consumers should be aware that purchasing local food has implications for biodiversity and landscape, local employment, fair trade and social justice [4]. Brown et al. [3] studied commercial box schemes (in England and France) of local food produced approximately within $100 \mathrm{~km}$ radius and identified that customers have been motivated (to purchasing from the box scheme) by positive contribution to the ecosystem, food quality and pleasure. The increasing demand for organic, welfare-friendly and locally produced food is creating more opportunities for both existing farmers producing local food and for new entrants to farming.

Due to political desires to reshape rural spaces to market niche and quality food products and foster 'alternative' channels of food provision, local food is gaining prominence within debates how to encourage the explorations of the connections along the food chain, including links between producers and retailers [1,5]. Therefore, more research is needed to get better understanding on consumers' perceptions of local food, the impact of local foods on rural-urban interactions and the problems re- 
lated to local food systems. Usually, consumers perceive local food as "expensive" and not available at the right time with required quantity as local sourcing is often seasonal [3].

In Sweden, farmers markets have existed for hundreds of years enhancing the delivery of products from local producers to consumers $[2,6]$. Although open-air markets exist mainly during the harvest season (August to October), they have social, cultural and economical benefits as they are integrating producers and consumers. However, from logistics point of view, the main problem related to such selling system (open-air market) is that the producers drive their own cars and also most of the buyers drive to the market place. This leads to congestion and increases emissions of greenhouse gases [2,6]. Similar problem related to local food distribution was reported by Coley et al. [4] i.e. for large-scale vegetable box system, the bulk of the emissions arise not from chilling or mass transportation to regional hubs using heavy goods vehicles but the final delivery phase using light goods vehicles. This indicates that the local food delivery systems should be evaluated based on the specific situations of producers and customers in the area/ region under consideration. Also, logistic cost has been a bottleneck for small and local food producers to compete with large scale and conventional food supply systems.

These logistic related problems can be counteracted by creating efficient logistics systems adaptable for local food systems such as coordinated box-scheme delivery systems, direct sale (example to restaurants, schools), integration into large scale food distribution systems and planning optimized food delivery routes[6,7]. Such logistics improving efforts should be supplemented by successful planning and designing efficient distribution systems [8]. Freidberg and Goldstein [9] pointed out that as local food is scarce on market, researches should focus not only on quality of food but also on building genuinely alternative food supply networks. In the current study, the Roslagslådan LPOF supply network (see Fig- ure 1) which is operating in Roslag region, in Sweden, has been investigated.

\subsection{Roslagslådan LPOF Supply Network}

Roslagslådan network is located in the region of Roslag that is located in the Stockholm and Uppsala provinces, Sweden (see Figure 2). In the region of Roslag, there is an economic association known as Roslagsmat established for small scale, local farmers and food producers and it promotes "local food with identity and quality". At present, it has around 20 members who produce organic food and sell directly to consumers and to retailers. The produces are diversified but they are traceable and KRAV certified. KRAV is the Swedish labelling certification that a product has been organically produced without using any synthetic fertilizers and pesticides and the livestock raising does not rely on feed additives. However, this certification does not guarantee quality [11].

In May 2006, the association initiated a pilot project to explore and develop marketing channels for small scale food producers in the region. As a result the concept of Roslagslådan food supply network emerged with the basic purpose to avoid unnecessary transport distance and logistics cost and to promote LPOF with high quality. There are three companies which are main actors of the network (see Figure 1). They collaborate chiefly for mutual marketing and distribution benefits. They do have their own farms for growing organic food and also collect the produces from local farmers and distribute to the retailers and consumers.

\subsection{Main Characteristics of the Roslagslådan Network}

The main characteristics of the three main actors in the Roslagslådan network are presented in Tables $\mathbf{1}$ and 2. In addition to distributing LPOF to consumers, they also use on farm sale and open market sales which promote social connections and communications.

Table 2 indicates the distance of delivery routes varied

Table 1. Product type and means of delivery.

\begin{tabular}{|c|c|c|}
\hline Farm & Production type & Selling channel \\
\hline Company-1 & $\begin{array}{l}\text { Produces only herb-based products such as vinegars, oils, skin } \\
\text { products and teas; but also distributes vegetables (sourced } \\
\text { from Company-3) }\end{array}$ & Through Roslagslådan network (August-December) \\
\hline Company-2 & $\begin{array}{l}\text { Tomato, cucumber, aubergine, paprika, lettuce, capsicum, } \\
\text { carrot and snow peas but potatoes, celeriac, squash, leek, pars- } \\
\text { nips, onion, garlic, cabbage, broccoli, bean, corn, parsley, dill, } \\
\text { red beet and meat }\end{array}$ & $\begin{array}{l}\text { On site sell (July-September) ; Annual open market; } \\
\text { through nearby ICA supermarket (May-September); } \\
\text { through Roslagslådan network ( } 1 / 3 \text { of its harvest) (August- } \\
\text { October) }\end{array}$ \\
\hline Company-3 & $\begin{array}{l}\text { Vegetable (white, red and Savoy Cabbages), Root products } \\
\text { ( beet, carrot and parsnip) and } 17-20 \text { different varieties of } \\
\text { potatoes; sheep }\end{array}$ & $\begin{array}{l}\text { Through Roslagslådan network (August-December); via } \\
\text { Supermarkets; direct supply to restaurants }\end{array}$ \\
\hline
\end{tabular}

*Senneby farm rears a small number of sheep, which are slaughtered and sold locally during the winter; ${ }^{* *}$ Forsbergs Gris \& Grönt rears a number of sheep, which are slaughtered and used for wool production locally. 


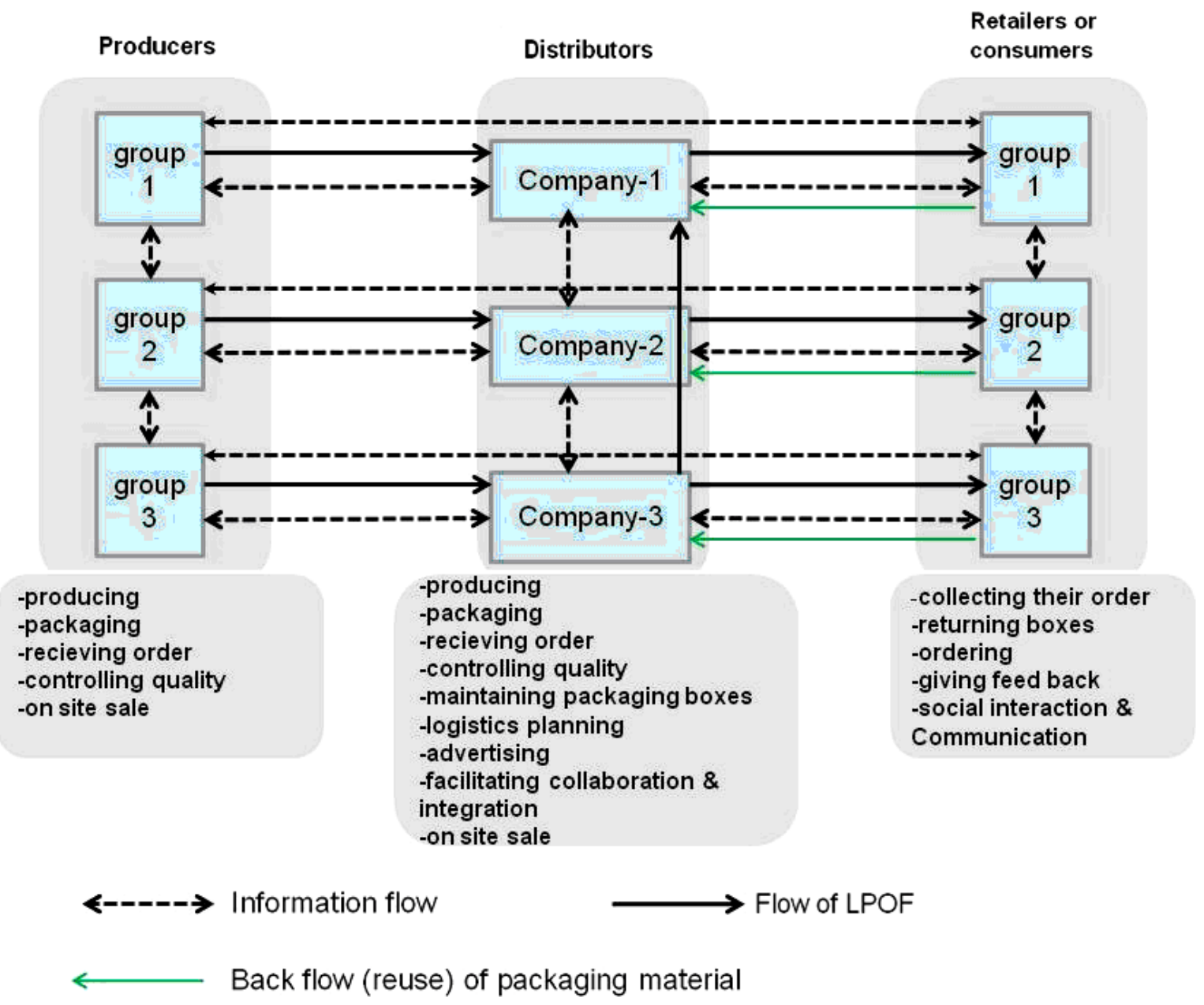

Figure 1. Concept of Roslagslådan food supply network. The information flow indicates how the social interaction is increased due to the network.

Table 2. Characteristics of the existing distribution routes.

\begin{tabular}{cccccc}
\hline \multirow{2}{*}{ Route } & \multirow{2}{*}{ Farm } & Vehicle type & $\begin{array}{c}\text { Vehicle Capacity } \\
{\left[\mathrm{m}^{3}\right]}\end{array}$ & $\begin{array}{c}\text { Route length } \\
{[\mathrm{km}]}\end{array}$ & $\begin{array}{c}\text { Total time } \\
{[\mathrm{h}: \mathrm{min}]}\end{array}$ \\
\hline Route 1 & Company-1 & Peugeot Expert van & 4 & 190 & $8: 00$ \\
Route 2 & Company-2 (route- I) & VW transporter & 5 & 174 & $5: 30$ \\
Route 3 & Company-2 (route-II) & Renault Kangoo & 2.8 & 109 & $4: 00$ \\
Route 4 & Company-3 (route-I) & Citroen Jumper 9HDI & 7.5 & 94 & $2: 36$ \\
Route 5 & Company-3 (route-II) & Vehicles of other transport company (collaborator) & N/A & 131 & N/A \\
\hline
\end{tabular}

"Collecting from production place and delivery to distribution point (complete route). It doesn't include the distance travelled (which varies from $624 \mathrm{~m}$ to 70 $\mathrm{km}$ ) by each of its customers to collects the produce from distribution point (see Figure 3).

from $94 \mathrm{~km}$ to $190 \mathrm{~km}$ while the respective transport time (including loading/unloading) varied from 2:36 hr: min to $8 \mathrm{hr}$. For Company-3, route-II covered the delivery from production area (Östhammar) to large cities, namely Uppsala and Stockholm and the vehicle used for delivery on this route was owned by external transport company (see Figure 2). About 23\% of the produces delivered by Company-3 was performed via its route-II.
For the remaining route (see Table 2) the companies used their own vehicles whose volume varies from $2.8 \mathrm{~m}^{3}$ to 7.5 $\mathrm{m}^{3}$.

Prior to the initiation of the Roslagslådan network, the members have experienced constraints associated with the logistics service. After garnering a pilot group of customers via a local newspaper advertisement, the three partners began planning logistical routes based on where 

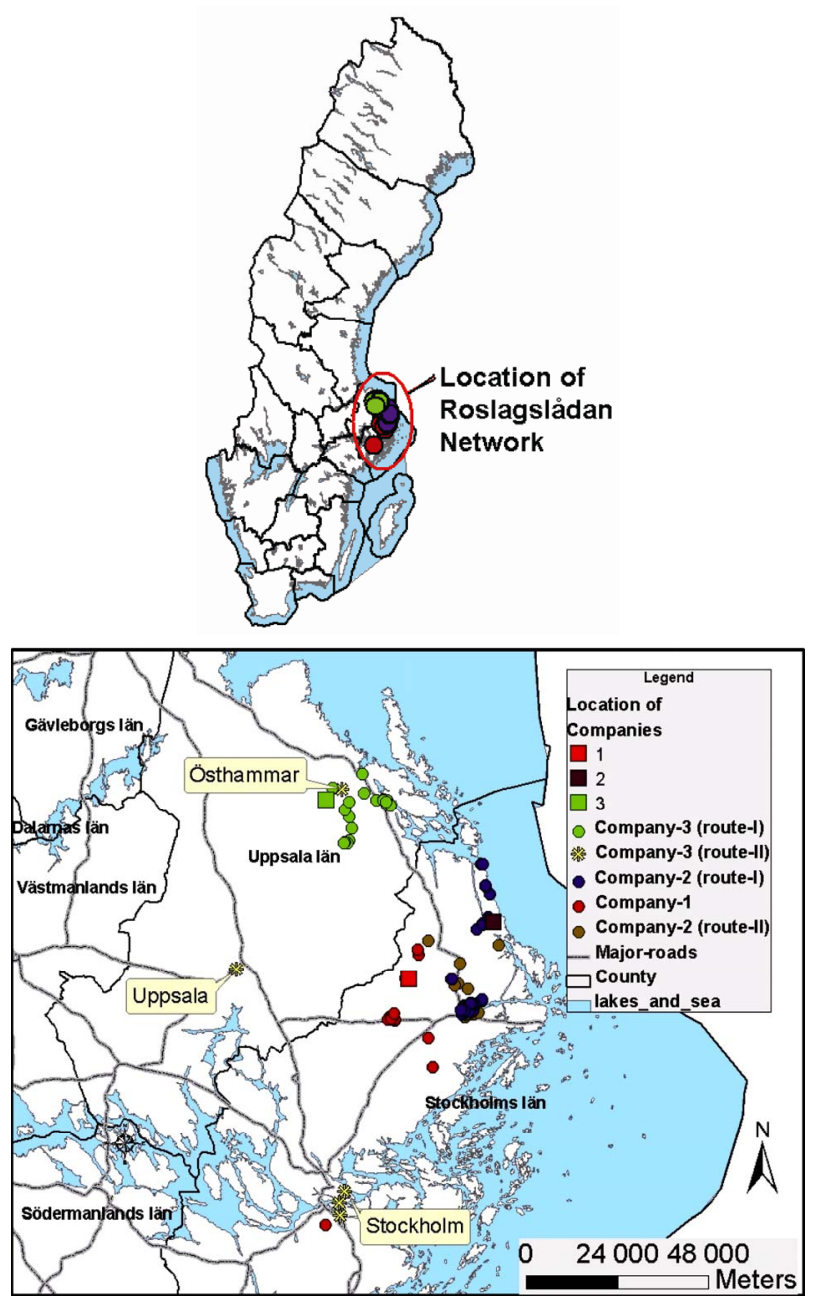

Figure 2. Location of study area and routes and customers in the Roslagslåda network.

their clients lived. After a period of trial and error, Roslagslådan network became a fully fledged delivery scheme in 2006 and over four years, the operation has developed a steady customer base, totalling approximately 150 regular customers.

The main objective of this study was to evaluate the logistics performances of the Roslagslåda network mainly in relation to transport distance and time and develop recommendation for improvement, in case of any gap identified. The specific objectives were to:

- Identify and map the locally produced organic food producers, distributors and delivery points in the Roslagslådan network

- Investigate the existing packaging condition, delivery frequency and quantity

- Investigate the existing collection and distribution routes

- Carry out route simulation/optimisation analysis in relation to transport distance and time
In summary, improving the logistics performance increase the competitiveness of local food producers and promote the sustainability of local food systems. In the existing situation, the Roslagslådan LPOF supply network is relatively good example of coordinated and integrated local food delivery system. However, the finding of this study indicated that further improvements could be gained by replanning more optimal routes and revising delivery time windows. The remaining part of this paper is structured as follows. In Section 2, the materials and methods are described. The results are presented in Section 3, while the main findings have been discussed in Section 4. Finally, the major conclusions have been drawn in Section 5.

\section{Materials and Methods}

In order to understand the characteristics of Roslagslådan LPOF supply network and map out its logistics activities, the information on packaging, the existing delivery routes, the type and capacity of vehicles used, the main bottlenecks or/and coordination in the food delivery systems were gathered and analyzed. The study was conducted through literature review, interviews, field measurements and route analysis (simulation and optimisation).

\subsection{Data Collection}

In order to complement the literature review, the three main actors in the Roslagslådan network and some of their customers were interviewed. These interviews were conducted face-to-face, via telephone, and via email. In addition to conducting interview, field measurements were carried out in September and October months, 2009. Data collection on the coordinates of location of producers, distributors, distribution points and food collection/ distribution routes was done using the global positioning system (GPS). Two pieces of portable GPS receivers and a stop watch were used. The portable GPS receivers were used to collect information about points along 5 delivery routes including time and coordinates of required locations. The recorded and stored data could be uploaded to PC with the help of USB interference cable. The second GPS receiver was used to quickly capture coordinates of all stops or distribution points where, simultaneously vehicles' arrival and departure times, the numbers of delivered boxes and customers' postal addresses were registered.

\subsection{Mapping the Project Area}

The location of the three distributing companies and their delivery points in the network were mapped with ArcMap of GIS software [12] utilizing the coordinates of each point recorded during data gathering and field measure- 
ment (see Figure 2). The distribution Company-1 is located at $59^{\circ} 50^{\prime} 28^{\prime \prime} \mathrm{N}$ latitude and $18^{\circ} 26^{\prime} 31^{\prime \prime} \mathrm{E}$ longitude while Company- 2 is located at $59^{\circ} 58^{\prime} 01^{\prime \prime} \mathrm{N}$ latitude and $18^{\circ} 50^{\prime} 56^{\prime \prime}$ E longitude and Company- 3 is located at $60^{\circ} 16^{\prime} 19^{\prime \prime} \mathrm{N}$ latitude and $18^{\circ} 05^{\prime} 06^{\prime \prime} \mathrm{E}$ longitude. Company- 2 owns farm area that covers about 6.15 hectares in its three open fields and one green house $\left(650 \mathrm{~m}^{2}\right)$. Company-3 own farm land that covers about 20 hectares. Customers of Roslagslådan network are Restaurants, retailers and non business people. Also, the distribution may be to working places, direct to residents and to public waiting places.

\subsection{The Existing Distribution System}

In addition to on farm sale, the three main companies distribute their products to their customers. Company-1 collects the food products from the farm owned by Company-3 and also from at least two other producers of small quantity (see Figure 3). Then it transports the products to a distribution point located at $59^{\circ} 44^{\prime} 35^{\prime \prime} \mathrm{N}$ and $18^{\circ} 22^{\prime} 03^{\prime \prime} \mathrm{E}$ longitude, which is about $14 \mathrm{~km}$ away from the place of Company-1. From the distribution point, about 15 customers collect the products. One of the customers is found in Stockholm, about $67 \mathrm{~km}$ far away from the distribution point. For the remaining 14 customers the distance from the distribution point varies from $1 \mathrm{~km}$ to $25 \mathrm{~km}$.

Company-2 uses two routes (route-I and route-II) to distribute LPOF to a distribution point and directly to the place of some customers (see Figure 4). The company first loads the produces from its own farm and then on the way to distribution it picks the produces of small producers and distributes directly to some of its customers and to a distribution point from where some customers collect their orders.

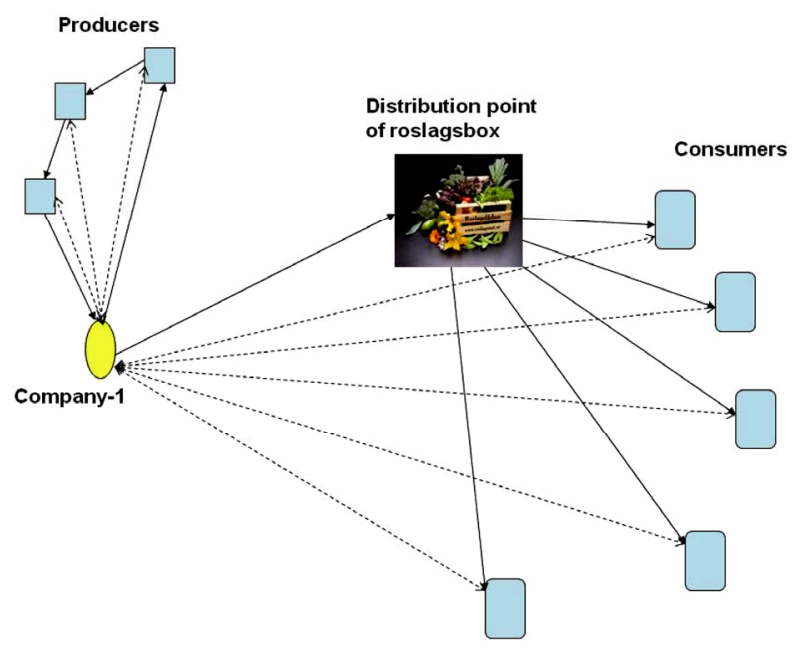

Figure 3. The current distribution system of Company-1.
Similar to Company-2, the distributing Company-3 has two delivery routes (see Figure 5). In its surrounding area, the company uses route-I while route-II reaches delivery points located at Östhammar, Uppsala and Stockholm (three places in Stockholm) cities (see Figure 2 and 8(c)). The company delivers only to Östhammar from where the products are distributed further to Uppsala and Stockholm by other external transporter (collaborator).

\subsection{Route Analysis}

Using Route LogiX software [13] and data gathered during field measurement, route optimization analysis was done to investigate the optimality of the current distribution routes of food products and to analyze the new distribution route based on different scenarios. RoutelogiX software has most powerful vehicle routing and it finds optimised routes by minimizing driving distance and time, which in turn reduces transport cost and emission of green house gases [13]. In total, seven different routes

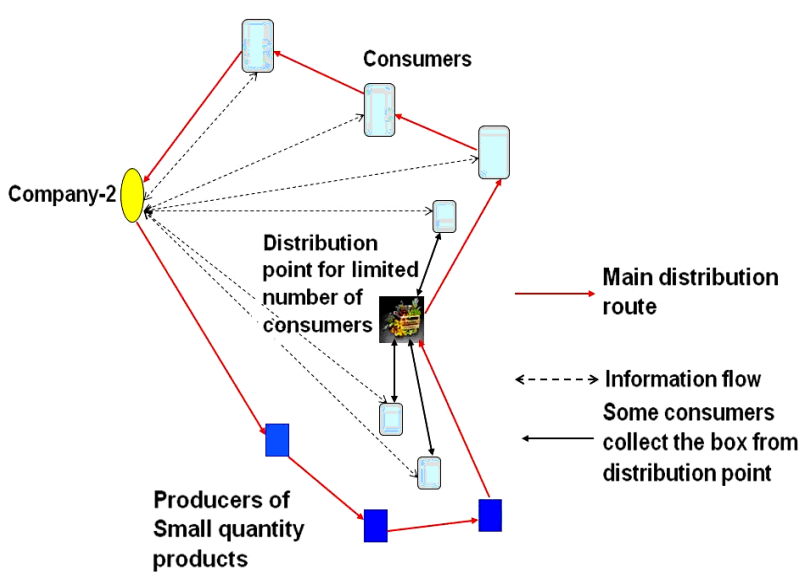

Figure 4. The current distribution system of Company-2.

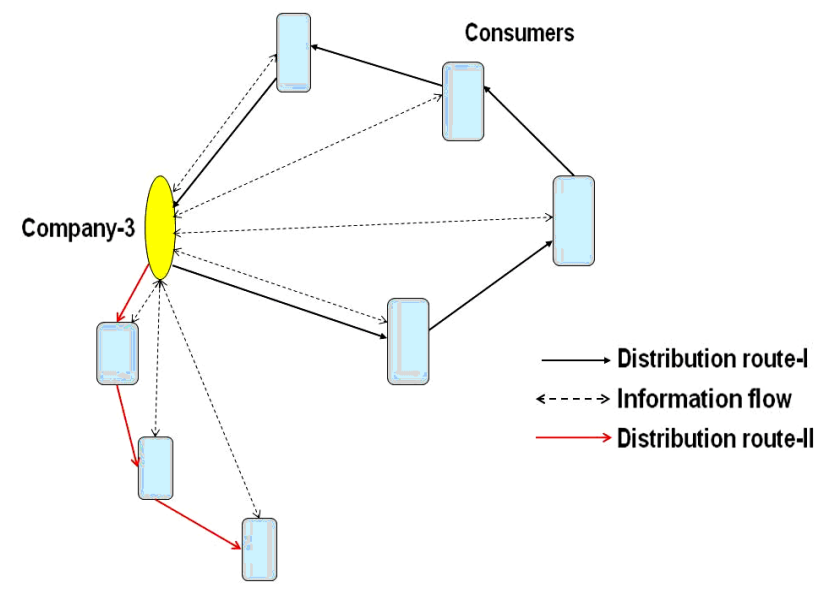

Figure 5. The current distribution system of Company-3. The producer distributes to its customers. 
were analysed for the three distributing companies of Roslagslådan LPOF supply network.

\subsubsection{Routes of Company-1}

For Company-1, four routes i.e. a single collection route and three distribution routes were studied. For the collection route, first the existing route distance and delivery time was determined and thereafter the route was optimised. For the distribution routes, three scenarios were considered.

\subsubsection{When Company-1 Delivers to a Distribution Point from Where Customers Collect Their Orders}

This scenario is the same as existing route where the company transport the products to the distribution centre located at $59^{\circ} 44^{\prime} 35^{\prime \prime} \mathrm{N}$ latitude and $18^{\circ} 22^{\prime} 03^{\prime \prime} \mathrm{E}$ longitude. The route analysis was done with and without including the customer in Stockholm, because the customer in Stockholm is relatively far from the area where Company-1 operates, and its impact on the simulation results is high in relation to driving distance and time.

\subsubsection{When Company-1 Distributes Products Directly to Its Customers}

In this case, the company delivers to each customers. Similar to scenario 1 , the simulation analysis was done including and excluding the customer in Stockholm.

\subsubsection{Scenario 3: When Only the Delivery to the Distribution Point is Considered}

In this case, the company delivers only to the distribution place, from where its customers collect their order. However, in Scenario 3, the transport distance and time was simulated only for the delivery to the distribution place, neglecting the transport distance and time taken by each customer to collect their order taking into consideration that most of the customers might collect their order on the way from job or other trip.

\subsubsection{Routes of Company-2}

There were two distribution routes for this company. In both cases, first the route distance and travel time were simulated for existing (unoptimized) route (i.e. following the order of visiting each customer) and then the routes were optimized. The transport distance and time determined for optimized routes were compared to that of unoptimized routes.

\subsubsection{Combined Distribution Route for Company-1 and Company-2}

In this case, a single route was proposed for distributing the products to all the customers of the two companies. The optimized driving distance and total time of this new route was compared to the sum of the three existing routes i.e. scenario-1 of Company-1 (excluding its customer in Stockholm) and the two routes of Company-2. The distance and time were determined for the combined and optimized route considering the address of Company-2 as starting and end point of the delivery tour on this new route.

\subsubsection{Routes of Company-3}

For this company, the route distance and travel time were determined for unoptimized and optimized cases of its two routes and then the unoptimized and optimized routes were compared. In route II, simulation was done taking into consideration the case when a single transporter (collaborator) picks the products from Östhammar, on the way from job (therefore, only one way journey was considered) and transports to the customers in Uppsala and Stockholm cities.

For all the three companies, the comparison analysis was done using the driving distance and total time determined for optimised and unoptimised routes. However in this comparison analysis, the driving distance and time considered for the existing routes, were not the measured values, but the simulated values. This was preferred in order to make the analysis approach consistent, because for some scenarios, there were no distance and time values recorded for the routes.

In all cases, the loading and unloading time was estimated based on the information gathered during field measurement and interview. For loading time (for each company) 15 to 30 minutes was considered depending on the volume of produces loaded. The unloading time (including delivery time) was taken to be equal to 2 minutes on average for each customer. When picking products (during product collection) the loading time at the place of each producer (producing small quantity) was considered to be about 5 minutes.

During the field measurement it was learnt that the existing delivery routes were formed based on the delivery time window set by the customers. The distribution companies try to fulfil the need of customers although the order of visiting the customers seems to be uneconomical.

\section{Results}

\subsection{Packaging}

Transporting fresh producers requires appropriate packaging. A wooden box, locally produced from pine was used as the standard packaging material (see Figure 6). The box is known as Roslagslåda and it is reused. In addition to the wooden boxes, paper bags are available and used to complement the box when there is additional order. The paper bag is also used when customer chooses 
it rather than wooden box. The sizes of the wooden box and paper bag are $25 \times 30 \times 40$ and $35 \times 25 \times 17 \mathrm{~cm}$ respectively. Each delivery time the wooden box or paper bag contains 8 to 10 different types of fresh vegetables and root vegetables.

\subsection{Delivery Quantity and Frequency}

Considering the delivery amount observed during the field measurement, about 134 boxes were distributed by the three companies per delivery day. Large number of boxes (about 111) was distributed by Company- 2 while Company-1 and Companu-2 delivered about 17 and 26 boxes respectively. About 71 delivery points (customers) were recorded for Company-2. Company-3 had 30 delivery points while for Company-1, only 15 delivery points were recorded (see Figure 7).

All three companies carried out the distribution of LPOF once in two weeks period from August up to October. The deliveries of Company-1 and Company-3 extend until December. Company-1 also delivers once a month in January and February.

\subsection{Route Analysis}

Table 3 presents the result of route simulation/optimisation analysis for the delivery routes of the three companies. For Company-1, the simulated driving distance and total time for unoptimised collection route were about $225 \mathrm{~km}$ and 3:49 hr:min respectively. For this route, there was no improvement obtained from optimisation analysis indicating that the existing collection route is optimum (see Table 3).

Comparing scenario-2 with scenario-1 (Company-1), the driving distance and total time (excluding customer in Stockholm) were reduced from $282 \mathrm{~km}$ to $119 \mathrm{~km}$ and from 6:48 hr:min to 3:42 hr:min. This indicated that the driving time and transport distance were improved by about $58 \%$ and $46 \%$ respectively. In scenario-3, the driving distance and total time were about $29 \mathrm{~km}$ and 54 minutes (i.e. to deliver to the distribution point). When compared to the existing route of scenario-1, scenario3 improved the driving distance by $76 \%$ and total time by $74 \%$.

Concerning Company-2, for route-I (Figure 4), the distance was reduced from $156 \mathrm{~km}$ to $140 \mathrm{~km}$ while the time was reduced from 5:36 to 5:12 hr:min indicating that the distance and time were improved by $10 \%$ and $7 \%$ respectively. Similarly for route- 2 , the driving distance was reduced from $194 \mathrm{~km}$ to $149 \mathrm{~km}$ while total time was reduced from 6:54 hr:min to $6: 13 \mathrm{hr}: \mathrm{min}$ respectively indicating that the distance and time were reduced by $23 \%$ and $10 \%$ respectively.

Regarding the combined routes of Company-1 and Company-2 (see Figure 8a), the sum of distance for the three existing routes (scenariol of Company-1 and two routes of Company-2) was about $632 \mathrm{~km}$ and the respective total time was 19:18 hr:min. By using the new combined route, the total distance and time were reduced to $287 \mathrm{~km}$ and 12:41 hr:min which implied the improvement of $55 \%$ and $34 \%$ for transport distance and time respectively.

Regarding Company-3, for route-I (Figure 5), the transport distance (unoptimised) was $160 \mathrm{~km}$ and the corresponding total delivery time was 5:39 hr:min. When optimized, the figures reduced to $108 \mathrm{~km}$ and $4: 44$ hr:min which meant improvement of $32 \%$ for distance and $16 \%$ for time. For route-2, the analysis result indicated that the transport distance and time (single trip) are $163 \mathrm{~km}$ and 3:34 hr:min and the optimization analysis

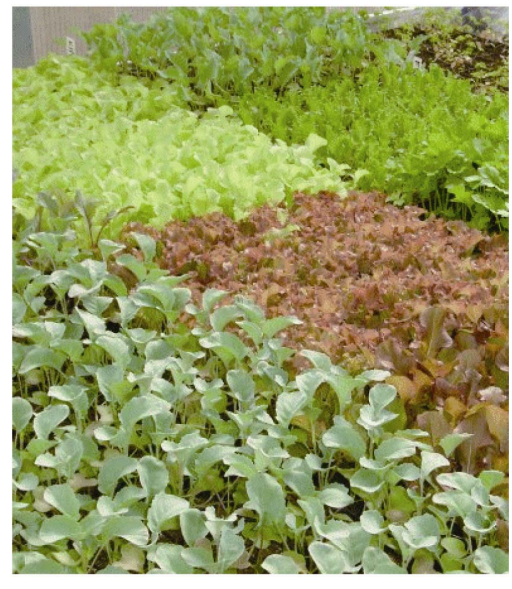

(a)

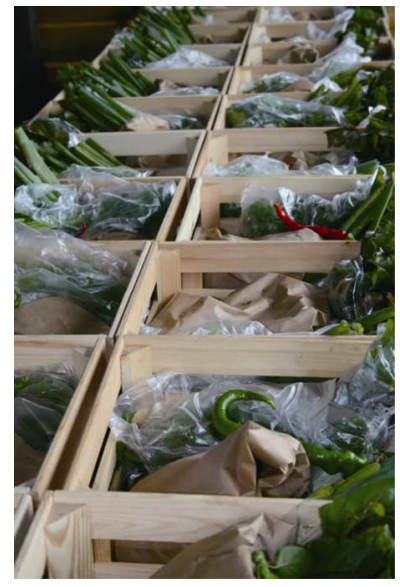

(b)

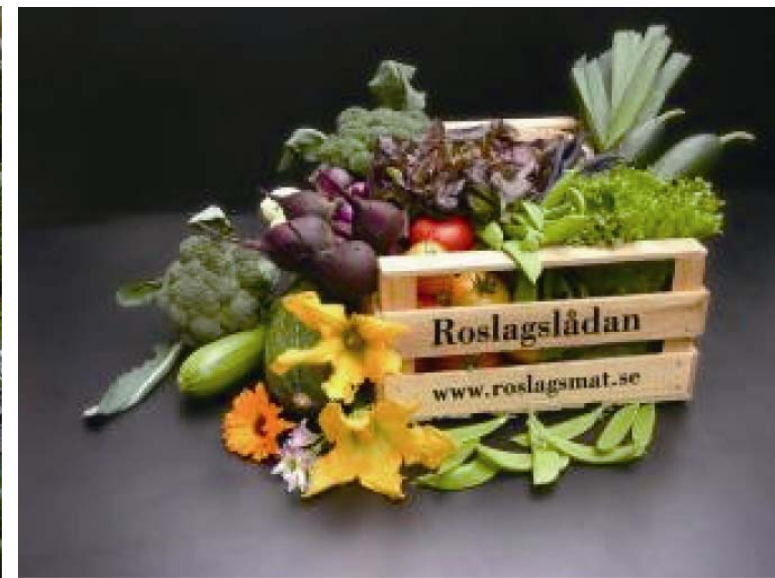

(c)

Figure 6. LPOF products of Company-2. (a) Organic vegetables on the farm field owned by Company-2; (b) boxes filled with LPOF and ready for distribution by Company-2; (c) standard box of Roslagslådan network (source www.sennebytradgard.nu and www.roslagsmat.se). 


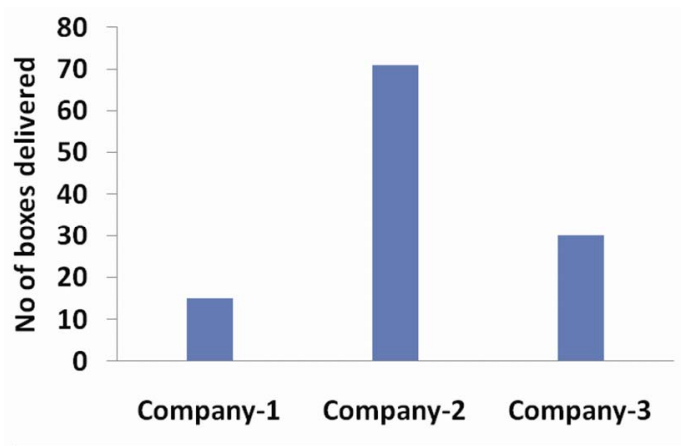

(a)

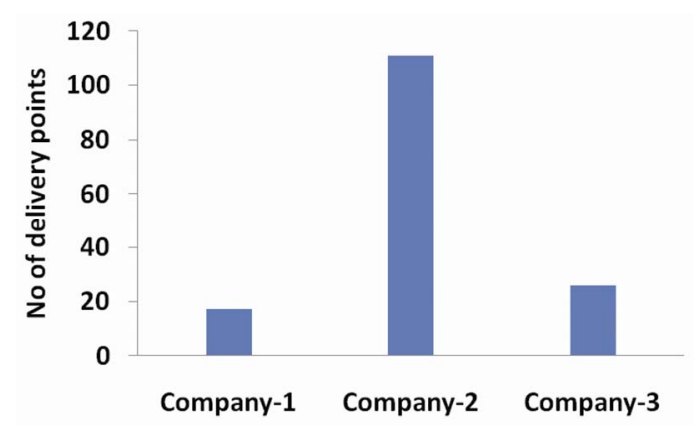

(b)

Figure 7. Number of delivery quantities and delivery points recorded for each company. (a) The number of boxes delivered on each delivery day (once in 2 weeks); (b) the number of delivery points recorded during field measurements.

indicated that the existing route (route-2) is optimum. Figure 8 presents examples of unoptimized and optimized routes.

\section{Discussions}

Nowadays, in relation to food safety and food security, the demand for locally produced food is increasing and the local food systems are being considered as alternative strategies to conventional large scale food supply chains [14-16]. This situation helped the companies in the Roslagslådan network to gain costumers acceptance in relatively short time and with less expenses to introduce their marketing concept.

Roslagslådan is one example of business networks that could facilitate some of the social and economic benefits of local food systems. When food supply systems operate as networks, social benefits such as potential for mutual learning, reduced transaction costs, social cohesion and competitive strengths emerge [17-21].

The members of the network are dedicated to satisfy the consumers by supplying food with identity and quality. For example, the crops are allowed to mature in the field to their specific requirements and they deliver fresh produce to consumers. However, due to seasonal constraints, the varieties of vegetable to be supplied during every distribution tour should be decided by the supplier depending on the season and available produces.

The Roslagslådan LPOF supply network could facilitate the flow of information (see Figure 1). It created good opportunity for the customer and the producers to have contact and that helps the producer to get direct response from the customers. Newsletters are distributed with the delivery boxes outlining the varieties included in the box, source of the produce and its price, relevant information about the vegetables and recipes for some produces which are uncommon in the region. The newsletter also includes contact details, any relevant news or communication and additional produce available for customers to purchase through Roslagslådan network from other members of Roslagsmat. Such a local food brand, with assurance of sustainability and quality, increases consumers' confidence [7].

There is internet based flow of information between consumers, producers and distributing companies. The customers could order the products by telephone or subscribing via internet. The distributors contact the small producers before starting the distribution and collect the boxes from each small producer and perform the distribution. The three main actors also play key role in advertising the LPOF in the region. In addition to using newsletters, in the region, the association arranges market days 3 times per year between the months of August and September mainly to promote the direct contact between producers and consumers and increase consumers' confidence on the produces.

From the results of route analysis, it was noted that the simulated value of route distance showed some deviation from the value recorded during field measurement due to different measurement errors and/or possible road changes (i.e. the road embedded in the software may deviate from the actual road the driver could use). Therefore, it would be more realistic to do the comparison analysis based on the simulated values, omitting the recorded values which were available only for some of the routes (see Tables 2 \& 3).

The route optimization analysis revealed that some of the existing routes were nearly optimal, for example the collection route for Company-1 and the distribution routeII of Company-3. On the other hand, significant improvements were gained for some routes. Good improvements noticed in the distribution routes of Company-1 (e.g. for Scenarios 2, up to $58 \%$ for distance and $46 \%$ for time), Company-2 (up to $23 \%$ for distance and $10 \%$ for time) and Company-3 (up to $32 \%$ for distance and 16\% for time) (see Table 3).

The highest improvement was observed for the scenario3 for distribution route of Company-1, i.e. $76 \%$ for distance and $75 \%$ for time. In scenario 3 it was assumed 
Table 3. Summary of route analysis for product collection and distribution by the three companies.

\begin{tabular}{|c|c|c|c|c|c|}
\hline & Route & Driving distance & Total time & $\begin{array}{l}\operatorname{Imp} \\
\text { dist }\end{array}$ & \\
\hline & Optimized Collection Route & 225 & $3: 44$ & 0 & 0 \\
\hline & $\begin{array}{c}\frac{\text { Distribution Route }}{\text { Scenario1 }} \\
\text {-With customer in Stockholm }\end{array}$ & 414 & $8: 27$ & & \\
\hline Company-1 & -Without customer in Stockholm & 282 & $6: 48$ & & \\
\hline & $\begin{array}{c}\text { Scenario2 } \\
\text {-with customer in Stockholm }\end{array}$ & 243 & $5: 05$ & 41.26 & 39.84 \\
\hline & -without customer in Stockholm & 119 & $3: 42$ & 57.85 & 45.59 \\
\hline & $\begin{array}{c}\text { Scenario } 3 \\
\text { Delivery to distribution point }\end{array}$ & 29 & $0: 57$ & 75.63 & 74.32 \\
\hline & $\frac{\text { Route-I }}{\text { Unoptimized }}$ & 156 & $5: 36$ & & \\
\hline Company-2 & Optimized & 140 & $5: 12$ & 10.34 & 7.14 \\
\hline & $\frac{\text { Route-II }}{\text { Unoptimized }}$ & 194 & $6: 54$ & & \\
\hline & Optimized & 149 & $6: 13$ & 23.14 & 9.90 \\
\hline Combined route of & Summation of existing 3 routes & 632 & $19: 18$ & & \\
\hline company-1 \& company-2 & New combined route & 287 & $12: 41$ & 54.62 & 34.28 \\
\hline & $\begin{array}{c}\frac{\text { Route-I }}{\text { Existing (Un optimized) }} \\
\text { Optimized }\end{array}$ & $\begin{array}{l}160 \\
108\end{array}$ & $\begin{array}{l}5: 39 \\
4: 44\end{array}$ & 32.14 & 16.22 \\
\hline Company-3 & & & & & \\
\hline
\end{tabular}

that the customers could collect the produce from distribution point. Although, this option show good improvement it should be noted that this option might not satisfy the need of some customers who could not collect the produce from distribution centre. The other problem related to this selling system (scenario-3) is that the buyers drive their own cars to the distribution centre, which in turn leads to congestion and increases emissions of greenhouse gases $[2,6]$. Good improvement (upto 55\% for distance and $34 \%$ for time) was also seen when the combined distribution route was considered for Company-1 and Company-2. This showed that integrating the distribution activities of the actors and optimising the route could result in significant savings and this confirmed the findings of previous researches $[7,8]$.

The reduction in the driving distance led to positive improvement towards environmental issue by reducing emission. However, from practical point of view, it is needed to consider other factors such as changing the delivery time window and using vehicles of more capacity (eg. for combined route of Company-1 and Com- pany-2), in order to implement the optimised routes. This is not easy for the distributors as they give priority to the customers need and it might be difficult for some customers to be flexible easily. However, improving the delivery time window might be facilitated through discussion between customers and distributing companies.

Due to the increasing concern on environmental degradation and energy crises, effective logistics networks should consider not only economic and operational performance but also the environmental sustainability of food supply networks [22]. In the future, as the Roslagslådan network expands or changes, updating the design of optimal delivery routes with best possible delivery time windows, is recommendable to strengthen the sustainability of the system. The continuation of this study addresses the environmental, economical, and management issues related to the sustainability of the Roslagslådan LPOF supply chain.

\section{Conclusions}

This study mapped out the supply chain of LPOF (locally 


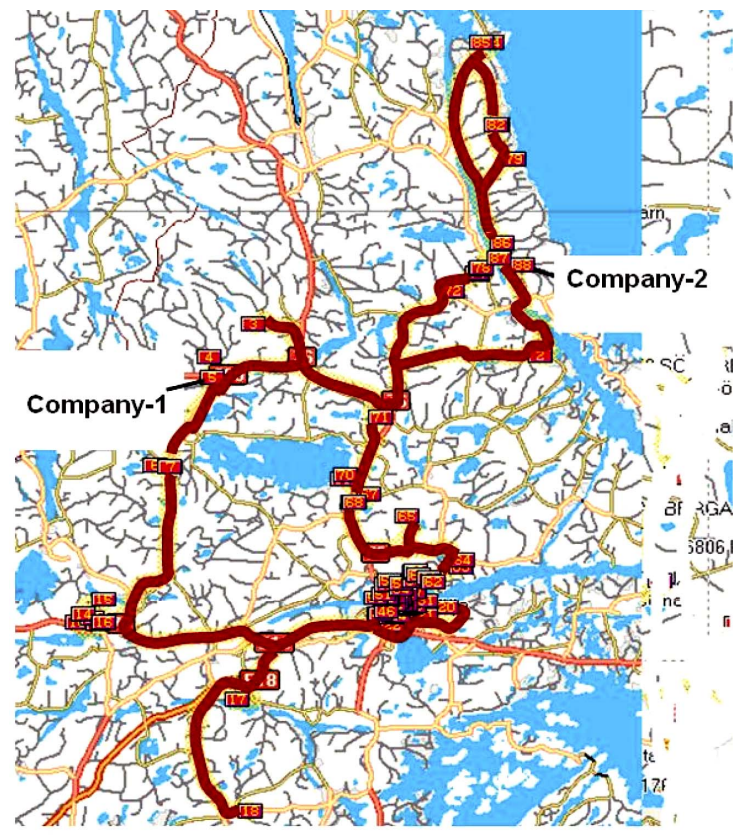

(a) Combined route for company1 and company-2

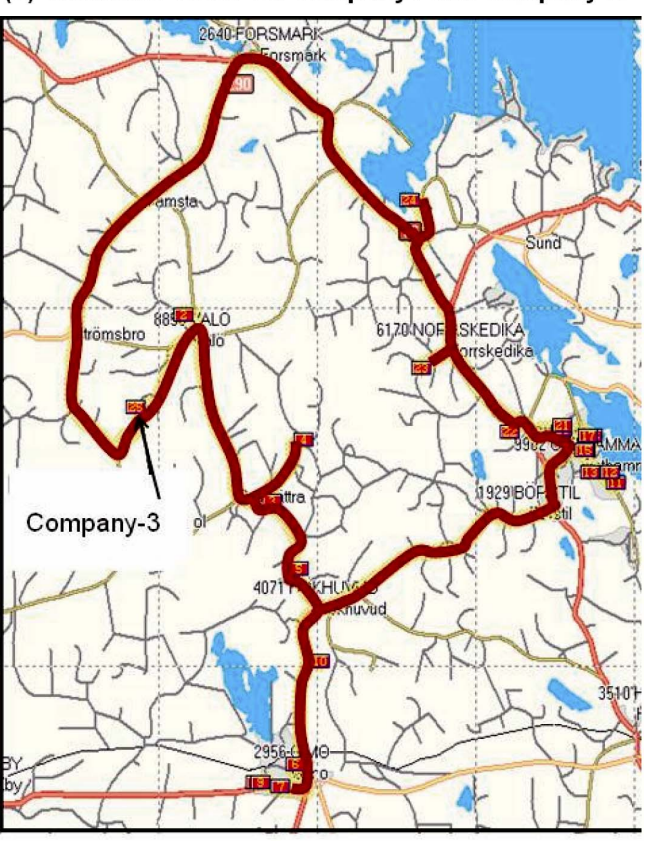

(c) Route-I, optimized

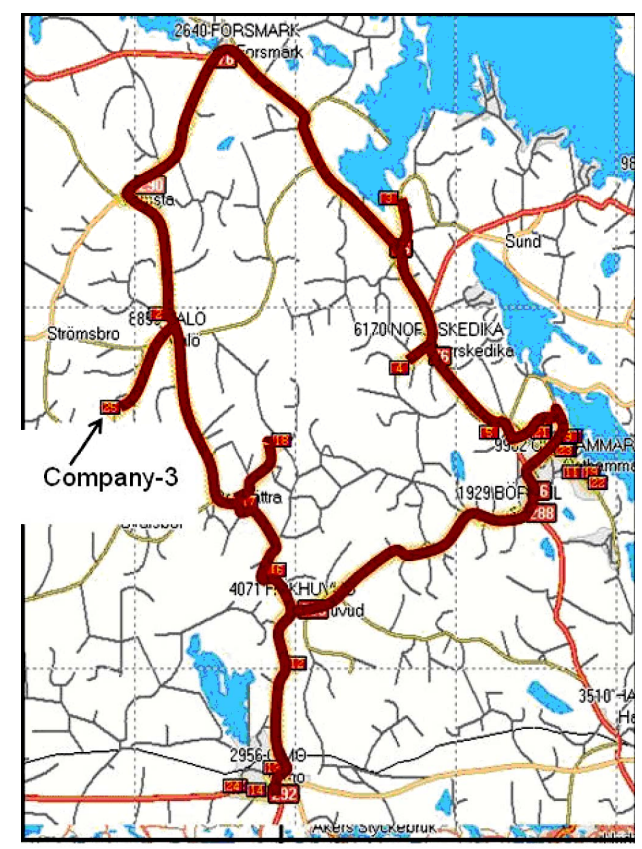

(b) Route-I, un-optimized

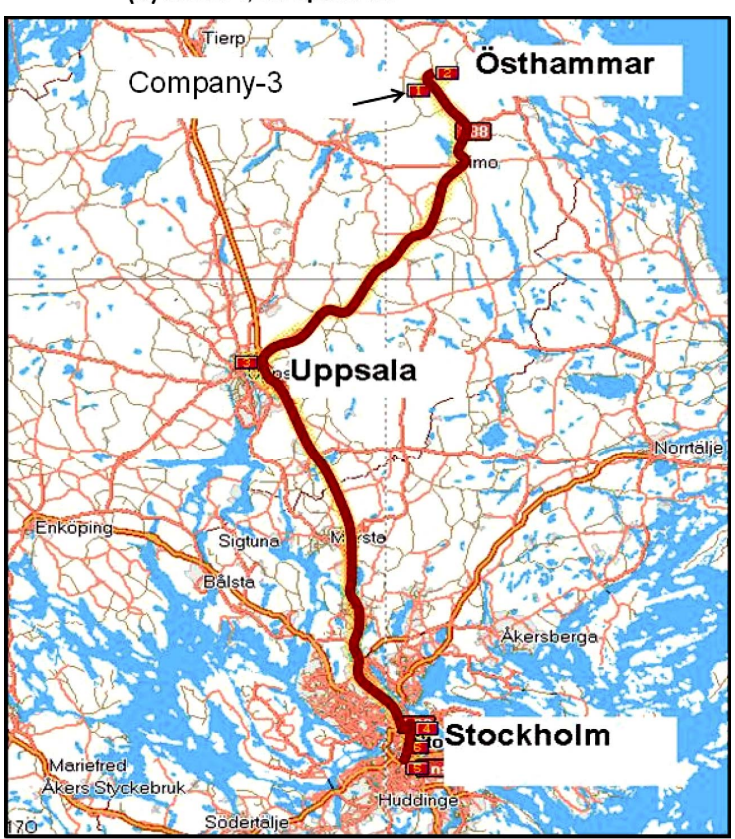

(d) Route-II

Figure 8. Examples of distribution routes. (a) presents the combined route of Company-1 and Company-2; (b) and (c) show unoptimized and optimised routes of Company-3 . (d) illustrates route-II of Company-3, the case where the existing route has been found to be the best.

produced organic food). As a case study, Roslagslådan food supply network, in which three LPOF distributing companies are the main actors, was investigated with the main aim of evaluating its logistics performance. The study was based on literature review, interview, field measurement and route simulation and optimisation (in terms of route distance and driving time) analysis.

The three companies in the Roslagslådan network distribute about 134 boxes of LPOF to about 116 delivery points, once in two weeks period mainly during AugustOctober, with 5 different distribution routes. The products are mainly vegetables and herb-based products. In 
addition to the distributing via Roslagslådan food supply network, the partners of the network uses also other means of selling: on farm sale, open market sales and selling via supermarket.

The locations of the distributing companies and delivery points (customer locations) were mapped using ArcMap of GIS software. The route simulation and optimisation analyses were conducted utilizing Route LogiX software. The route optimisation analysis indicated that for all the three distributors significant savings were noted in terms of route distance and delivery time. The savings in distance were $76 \%, 23 \%$ and $32 \%$ for Company-1, Company- 2 and Company-3 respectively. The corresponding savings in delivery time were $75 \%, 10 \%$ and $16 \%$. This leads to positive improvement toward the environmental and economical issues enhancing the sustainability of local food systems.

\section{REFERENCES}

[1] L. Nichol, "Local Food Production: Some Implications for Planning," Planning Theory \& Practice, Vol. 4, No. 4, 2003, pp. 409-427. doi:10.1080/1464935032000146264

[2] H. Nilsson, "Local Food Systems from a Sustainability Perspective: Experiences from Sweden," International Journal of Sustainable Society, Vol. 1, No. 4, 2009, pp. 347-363. doi:10.1504/IJSSOC.2009.028906

[3] E. Brown, S. Dury and M. Holdsworth, "Motivations of Consumers That Use Local, Organic Fruit and Vegetable Box Schemes in Central England and Southern France," Appetite, Vol. 53, No. 2, 2009, pp. 183-188. doi:10.1016/j.appet.2009.06.006

[4] D. Coley, M. Howard and M. Winter, "Local Food, Food Miles and Carbon Emissions: A Comparison of Farm Shop and Mass Distribution Approaches," Food Policy, Vol. 34, No. 2, 2009, pp. 150-155. doi:10.1016/i.foodpol.2008.11.001

[5] B. Ilbery and D. Maye, "Retailing Local Food in the Scottish-English Borders: A Supply Chain Perspective," Geoforum, Vol. 37, No. 3, 2006, pp. 352-367. doi:10.1016/j.geoforum.2005.09.003

[6] C. Wallgren, "Local or Global Food Markets: A Comparison of Energy Use for Transport," Local Environment, Vol. 11, No. 2, 2006, pp. 233-251. doi:10.1080/13549830600558598

[7] T. G. Bosona and G. Gebresenbet, "Cluster Building and Logistics Network Integration of Local Food Supply Chain," Biosystems Engineering, Vol. 108, No. 4, 2011, pp. 293-302. doi:10.1016/j.biosystemseng.2011.01.001

[8] D. Ljungberg and G. Gebresenbet, "Mapping out the Potential for Coordinated Goods Distribution in Urban Areas: The Case of Uppsala," International Journal of Transport Management, Vol. 2, No. 3, 2004, pp. 161-172. doi:10.1016/j.ijtm.2005.07.001

[9] S. Freidberg and L. Goldstein, "Alternative Food in the Global South: Reflections on a Direct Marketing Initiative in Kenya," Journal of Rural Studies, in press. www.elsevier.com/locate/jrurstud

[10] J. Murdoch, "Networks-A New Paradigm of Rural Development?" Journal of Rural Studies, Vol. 16, No. 4, 2000, pp. 407-419. doi:10.1016/S0743-0167(00)00022-X

[11] KRAV, "Standards for KRAV-Certified Production". www.krav.se

[12] Economic and Social Research Institute, "ArcGIS Desktop Help," ESRI GIS Software Corporate, New York, 2008.

[13] DPS, "Route LogiX Professional V5.0.4.39," Distribution Planning Software Ltd., Halesowen, 2004.

[14] F. Curtis, "Eco-Localism and Sustainability," Ecological Economics, Vol. 46, No. 1, 2003, pp. 83-102. doi:10.1016/S0921-8009(03)00102-2

[15] M. M. Kroma, "Organic Farmer Networks: Facilitating Learning and Innovation for Sustainable Agriculture," Journal of Sustainable Agriculture, Vol. 28, No. 4, 2006, pp. 5-28. doi:10.1300/J064v28n04_03

[16] T. Marsden and E. Smith, "Ecological Entrepreneurship: Sustainable Development in Local Communities through Quality Food Production and Local Branding," Geoforum, Vol. 36, No. 4, 2005, pp. 440-451. doi:10.1016/j.geoforum.2004.07.008

[17] M. Nousiainen, P. Pylkkänen, F. Saunders, L. Seppnen and K. M. Vesala, "Are Alternative Food Systems Socially Sustainable? A Case Study from Finland," Journal of Sustainable Agriculture, Vol. 33, No. 5, 2009, pp. 566-594. doi:10.1080/10440040902997819

[18] A. Hughes, "Geographies of Exchange and Circulation: Alternative Trading Spaces," Progress in Human Geography, Vol. 29, No. 4, 2005, pp. 496-504. doi:10.1191/0309132505ph563pr

[19] L. Holloway, R. Cox, L. Venn, M. Kneafsey, E. Dowler and H. Tuomainen, "Managing Sustainable Farmed Landscape through 'Alternative' Food Networks: A Case Study from Italy," The Geographical Journal, Vol. 172, No. 3, 2006, pp. 219-229.

[20] A. Halinen and J. Törnroos, "Using Case Methods in the Study of Contemporary Business Networks," Journal of Business Research, Vol. 58, No. 9, 2005, pp. 1285-1297. doi:10.1016/i.jbusres.2004.02.001

[21] T. Eng, "The Effects of Learning on Relationship Value in a Business Network Context," Journal of Business to Business Marketing, Vol. 12, No. 4, 2005, pp. 67-101. doi:10.1300/J033v12n04_03

[22] W. D. Solvang and M. H. Hakam, "Sustainable Logistics Networks in Sparsely Populated Areas," Journal of service science and management, Vol. 3, No. 1, 2010, pp. 72-77. doi: $10.4236 /$ jssm.2010.31008 